\title{
Neuromonitoring of delirium with quantitative pupillometry in sedated mechanically ventilated critically ill patients
}

Eva Favre ${ }^{1,2,3 \dagger}$, Adriano Bernini ${ }^{1 \dagger}$, Paola Morelli ${ }^{1}$, Jerôme Pasquier ${ }^{4}$, John-Paul Miroz ${ }^{1}$, Samia Abed-Maillard ${ }^{1}$, Nawfel Ben-Hamouda ${ }^{1,2}$ and Mauro Oddo ${ }^{1,2^{*}}$ (D)

\begin{abstract}
Background: Intensive care unit (ICU) delirium is a frequent secondary neurological complication in critically ill patients undergoing prolonged mechanical ventilation. Quantitative pupillometry is an emerging modality for the neuromonitoring of primary acute brain injury, but its potential utility in patients at risk of ICU delirium is unknown.

Methods: This was an observational cohort study of medical-surgical ICU patients, without acute or known primary brain injury, who underwent sedation and mechanical ventilation for at least $48 \mathrm{~h}$. Starting at day 3, automated infrared pupillometry - blinded to ICU caregivers - was used for repeated measurement of the pupillary function, including quantitative pupillary light reflex (q-PLR, expressed as \% pupil constriction to a standardized light stimulus) and constriction velocity ( $\mathrm{CV}, \mathrm{mm} / \mathrm{s})$. The relationship between delirium, using the CAM-ICU score, and quantitative pupillary variables was examined.

Results: A total of 59/100 patients had ICU delirium, diagnosed at a median 8 (5-13) days from admission. Compared to non-delirious patients, subjects with ICU delirium had lower values of q-PLR (25 [19-31] vs. 20 [15-28] \%) and CV (2.5 [1.7-2.8] vs. $1.7[1.4-2.4] \mathrm{mm} / \mathrm{s})$ at day 3 , and at all additional time-points tested $(p<0.05)$. After adjusting for the SOFA score and the cumulative dose of analgesia and sedation, lower q-PLR was associated with an increased risk of ICU delirium (OR 1.057 [1.007-1.113] at day 3; $p=0.03$ ).

Conclusions: Sustained abnormalities of quantitative pupillary variables at the early ICU phase correlate with delirium and precede clinical diagnosis by a median 5 days. These findings suggest a potential utility of quantitative pupillometry in sedated mechanically ventilated ICU patients at high risk of delirium.
\end{abstract}

Keywords: Delirium, Pupillometry, Cholinergic, Pupillary reactivity, Mechanical ventilation

\footnotetext{
*Correspondence: mauro.oddo@chuv.ch

${ }^{\dagger}$ Eva Favre and Adriano Bernini contributed equally to this work.

${ }^{1}$ Critical Care Research Unit, Centre Hospitalier Universitaire Vaudois (CHUV),

University Hospital and University of Lausanne, Rue du Bugnon 46, BH08-623,

CH-1011 Lausanne, Switzerland

${ }^{2}$ Department of Intensive Care Medicine, Centre Hospitalier Universitaire

Vaudois (CHUV), University Hospital and University of Lausanne, Rue du

Bugnon 46, BH 08.623, Lausanne, Switzerland

Full list of author information is available at the end of the article
}

(C) The Author(s). 2020 Open Access This article is licensed under a Creative Commons Attribution 4.0 International License, which permits use, sharing, adaptation, distribution and reproduction in any medium or format, as long as you give appropriate credit to the original author(s) and the source, provide a link to the Creative Commons licence, and indicate if changes were made. The images or other third party material in this article are included in the article's Creative Commons licence, unless indicated otherwise in a credit line to the material. If material is not included in the article's Creative Commons licence and your intended use is not permitted by statutory regulation or exceeds the permitted use, you will need to obtain permission directly from the copyright holder. To view a copy of this licence, visit http://creativecommons.org/licenses/by/4.0/ The Creative Commons Public Domain Dedication waiver (http://creativecommons.org/publicdomain/zero/1.0/) applies to the data made available in this article, unless otherwise stated in a credit line to the data. 


\section{Introduction}

Delirium is a common neurological complication of intensive care unit (ICU), particularly in patients requiring prolonged mechanical ventilation and sedation. Delirium pathophysiology is multifactorial, involving abnormalities of microcirculatory and endothelial function, neurotransmitter imbalance, increased cytokine release and activation of neuroinflammation [1, 2]. The autonomous nervous system, through cholinergic activation, has an innate counterregulatory role against increased neuro-inflammation [3], via an inhibition of cytokine release and increased inflammatory neurotransmitters [4-7]. Growing evidence demonstrates that reduced functioning of the cholinergic antiinflammatory reflex is implicated in the pathophysiology of secondary critical illness-related brain dysfunction [8], which in turn can be attenuated by therapeutic vagus nerve stimulation [9-13].

The pupillary light reflex (PLR) is regulated by the cholinergic system, which mediates pupillary constriction to light stimulation [6]; therefore, quantitative measurement of the pupillary function with automated infrared pupillometry represents an attractive tool for evaluating cholinergic activity in the clinical setting [14-18] and is emerging as a novel monitoring and diagnostic tool in neurological conditions (e.g., Alzheimer's and Parkinson's disease) in which cholinergic deficit is implicated in disease pathogenesis [19-21].

Composite prediction scores (e.g., E-PRE-DELIRIC [22] and PRE-DELIRIC [23]) may help in improving delirium prediction [24]; however, there are currently no available quantitative tools for the monitoring of ICU delirium. The objective of this study was to examine in high-risk sedated mechanically ventilated patients, without primary acute or known brain injury, whether reduced pupillary light constriction-assessed quantitatively at the early phase of ICU using automated infrared pupillometry-was associated with delirium, assessed with the Confusion Assessment Method for the ICU (CAM-ICU) [25].

\section{Materials and methods Study population}

This was a prospective observational cohort study conducted from December 2016 to March 2018 at the Department of Adult Intensive Care Medicine, Centre Hospitalier Universitaire Vaudois (CHUV), University Hospital and University of Lausanne, Switzerland. Subjects were medical-surgical critically ill patients requiring sedation and mechanical ventilation for at least $48 \mathrm{~h}$, at high risk (about 50\%) of ICU delirium [26]. Exclusion criteria were mechanical ventilation for $\leq 48 \mathrm{~h}$, age $<18$ years, acute brain injury (including traumatic brain injury, ischemic/ hemorrhagic stroke, subarachnoid hemorrhage, hypoxicischemic brain injury after cardiac arrest, meningoencephalitis, status epilepticus, hepatic encephalopathy, neurosurgical intervention), previous known cognitive impairment, end-stage renal or hepatic disease (Child-Pugh B and $\mathrm{C}$ cirrhosis), pregnancy, ICU readmission, or transfer from another ICU. Additional exclusion criteria included a pre-existing ophthalmic condition or disease that may alter pupillary response, including cataract surgery, multiple sclerosis, amyloidosis, sclerodermia, and multiple system atrophy. Patients who were expected to die within $72 \mathrm{~h}$ were also excluded. A convenience sample size was used ( $n=100)$. The study was approved by the ethical committee of the Lausanne University (project-ID 2016-01923), and a waiver of consent was granted because non-invasive pupillometry is standard care. The study conforms with the STROBE guidelines for the report of observational studies.

\section{Management of analgesia and sedation}

Management of analgesia and sedation was based on a written institutional algorithm, in line with current recommendations [27]. Sedation was targeted to Richmond Sedation Agitation Scale (RASS) [28] with continuous infusions of propofol $(2-3 \mathrm{mg} / \mathrm{kg} / \mathrm{h})$ and/or midazolam. Propofol was generally first-line agent; midazolam was used in patients with hemodynamic instability (defined as norepinephrine $>0.25 \mu \mathrm{g} / \mathrm{kg} / \mathrm{min}$ ), or when the propofol dose exceeded $4 \mathrm{mg} / \mathrm{kg} / \mathrm{h}$ or was maintained for more than $48 \mathrm{~h}$. Analgesia was maintained with fentanyl $(1-1.5 \mu \mathrm{g} / \mathrm{kg} / \mathrm{h})$.

\section{Automated infrared pupillometry}

An automated infrared pupillometer (AlgiScan ${ }^{\oplus}$, IDMed, Marseille, France) was used for repeated measurements of quantitative PLR (q-PLR; expressed as the percentage change of pupillary diameter following the light stimulus) and constriction velocity (CV; measuring the speed of pupil constriction following light stimulation, expressed in $\mathrm{mm} / \mathrm{s}$ ). Normative values for the qPLR range between 30 and $40 \%$, and for the CV between 1.5 and $2.2 \mathrm{~mm} / \mathrm{s}$; low values are defined as a q-PLR < $20 \%$ and a $C V<1 \mathrm{~mm} / \mathrm{s}$, respectively [29].

Pupillary measurements were conducted on both eyes by an experienced clinician or nurse, who was not involved in patient care, and were performed during the day in stable conditions of ambient light. Measurements were performed twice daily (in the morning and the afternoon), starting at day 3 from mechanical ventilation, and were repeated at days 4 and 5 , up to a maximum of day 7. At each time-point, the average values of q-PLR and $\mathrm{CV}$ from both eyes were retained for the analysis. All pupillometry variables were blinded to clinicians and nurses involved in patient care.

\section{Outcome assessment}

As soon as the Richmond Agitation-Sedation Score was equal or greater than -2 , delirium was assessed twice 
daily until discharge from the ICU using the CAM-ICU. Patients were considered as having delirium when they had at least one positive CAM-ICU during their ICU stay. The duration of coma was calculated as the number of days spent with a motor Glasgow Coma Scale $<6$ from ICU admission.

\section{Data processing and statistical analysis}

Demographic and clinical variables included age, gender, medical versus surgical ICU admission, admission APACHE II score, daily SOFA score, sepsis diagnosis (according to the Sepsis-3 definition [30]), cumulative dose of analgesia (fentanyl) and sedatives (midazolam and propofol) during the first 7 days of ICU, duration of mechanical ventilation, length of ICU stay, and 90-day mortality.

Data are presented as median and interquartile range (IQR), except when otherwise stated. Univariate comparisons between the two main outcome groups (delirium vs. no-delirium) were analyzed using the non-parametric Wilcoxon test. A multivariable stepwise logistic regression model was performed by entering the day 3 q-PLR as the variable of interest, and the day 3 SOFA score, the cumulative fentanyl dose, and the cumulative dose of sedatives as pre-specified co-variates. Statistical significance was set at $p<0.05$. Statistical analysis was conducted with R 3.5.1 and JMP-14. The statistical analysis was performed by an independent statistician (JP).

\section{Results}

\section{Patient characteristics}

A total of 100 patients were studied. Patient demographics are summarized in Table 1 . The majority of patients had sepsis (76\%). Delirium prevalence was 59\%, and median time from ICU admission to delirium diagnosis was 8 days (IQR 5-13); 3 out of 100 patients died in the ICU, previous to CAM-ICU assessment, and were therefore not included in the final analysis. Mortality at 90 days was $10 \%$.

\section{Associations between ICU delirium and quantitative pupillary variables}

As shown in Table 2, patients with ICU delirium had higher SOFA score and received a greater 7-day cumulative dose of continuous infusions of midazolam and fentanyl, as compared with subjects without delirium. Patients with ICU delirium had also significantly longer duration of coma, mechanical ventilation, and ICU stay.

Compared to non-delirious subjects, patients with ICU delirium had lower values of q-PLR and CV, at all timepoints tested, starting at day 3 from mechanical ventilation, and up to day 5 (all $p<0.05$ for comparisons, Table 3). Trends over time of q-PLR and CV in delirious vs. non-delirious patients are illustrated in Fig. 1. In the
Table 1 Patient demographics

\begin{tabular}{|c|c|}
\hline Variable & Value \\
\hline Patient number & 100 \\
\hline Female gender, $n(\%)$ & $67(67)$ \\
\hline Age, years & $65(53-74)$ \\
\hline APACHE II score & $22(17-27)$ \\
\hline SOFA score & $12(9-14)$ \\
\hline \multicolumn{2}{|l|}{ Primary ICU admission } \\
\hline Pneumonia & $24(24)$ \\
\hline Peritonitis & $23(23)$ \\
\hline Cardiovascular surgery & $11(11)$ \\
\hline Chronic obstructive pulmonary disease & $11(11)$ \\
\hline Hemorrhagic shock & $9(9)$ \\
\hline Heart failure & $8(8)$ \\
\hline Pancreatitis & $6(6)$ \\
\hline Mediastinitis & $4(4)$ \\
\hline Polytrauma & $3(3)$ \\
\hline Medical admission, $n$ (\%) & $42(42)$ \\
\hline Surgical admission, $n$ (\%) & $58(58)$ \\
\hline Sepsis, $n(\%)$ & $76(76)$ \\
\hline Duration of coma*, days & $5(2-10)$ \\
\hline Duration of mechanical ventilation, days & $7(5-14)$ \\
\hline ICU delirium**, $n(\%)$ & $57(59)$ \\
\hline Days from ICU admission to delirium diagnosis & $8(5-13)$ \\
\hline ICU length of stay, days & $13(9-20)$ \\
\hline 90-day mortality, $n$ (\%) & $10(10)$ \\
\hline
\end{tabular}

Data are presented as median (25th-75th percentiles) or percentage (\%) Abbreviations: APACHE Acute Physiology and Chronic Health Evaluation, SOFA Sequential Organ Failure Assessment

*Duration of coma was defined as the number of days from ICU admission with a Glasgow Coma Scale-motor response $<6$; ${ }^{*} \mid \mathrm{ICU}$ delirium was evaluated twice daily with the CAM-ICU assessment; 3/100 patients died before CAM-ICU evaluation

subset of patients in whom pupillometry measurements were performed at days 6 and $7 \quad(n=30)$, q-PLR remained significantly lower in patients with delirium (median 22 [19-33] vs. 30 [29-43] in non-delirious patients at day 6, and 27 [25-31] vs. 35 [27-38] at day 7; both $p<0.05$ ).

\section{Reduced quantitative PLR at day 3 is a significant risk factor of ICU delirium}

By multivariable analysis, after adjusting for the SOFA score and the cumulative dose of midazolam and fentanyl, reduced q-PLR at day 3 was associated with an increased likelihood of ICU delirium (odds ratio 1.057; 95\% confidence interval 1.007-1.113, $p=0.03$ ) (Table 4).

A model combining SOFA score and q-PLR at day 3 yielded an area under the ROC curve of 0.71 for delirium prediction. Of note, independent associations 
Table 2 Univariate comparisons between patients with and without delirium

\begin{tabular}{|c|c|c|c|}
\hline Variable & Delirium $(N=57)$ & No delirium $(N=40)$ & $P$ value \\
\hline Age, years & $66(55-75)$ & $63(53-73)$ & 0.48 \\
\hline Female gender, $n(\%)$ & $17(30)$ & $16(40)$ & 0.38 \\
\hline Medical admission, $n$ (\%) & $25(44)$ & $16(40)$ & 0.83 \\
\hline Sepsis, $n(\%)$ & $45(79)$ & $29(73)$ & 0.48 \\
\hline APACHE $\|$ score, $n$ & $22(17-28)$ & $20(17-24)$ & 0.18 \\
\hline SOFA score, $n$ & $12(10-14)$ & $11(8-12)$ & 0.01 \\
\hline Midazolam, mg/kg* & $3.0(1.5-5.6)$ & $1.2(0.2-4.0)$ & 0.02 \\
\hline Propofol, mg/kg* & $125.6(24.9-238.4)$ & $94.4(51.9-278.2)$ & 0.90 \\
\hline Fentanyl, $\mu \mathrm{g} / \mathrm{kg}^{*}$ & $109.2(71.8-149.3)$ & $80.2(44.1-131.3)$ & 0.09 \\
\hline Duration of coma, days & $7(4-10)$ & $4(1-6)$ & 0.003 \\
\hline Duration of mechanical ventilation, days & $10(6-20)$ & $6(4-8)$ & 0.003 \\
\hline ICU length of stay, days & $14(11-25)$ & $10(6-14)$ & 0.001 \\
\hline 90-day mortality, $n$ (\%) & $3(5)$ & $4(10)$ & 0.44 \\
\hline
\end{tabular}

Data are presented as median (25th-75th percentiles) or percentage (\%)

*First 7 days cumulative dose received by continuous infusion

between delirium and q-PLR remained significant at days 4 and 5 . No statistically significant interaction was found between q-PLR and the dose of midazolam and fentanyl, at any time-point tested between day 3 and 5 (all $p>0.2$ ).

\section{Discussion}

This is the first clinical study investigating the role and potential utility of quantitative pupillometry in sedated mechanically ventilated medical-surgical ICU patients without initial acute or known primary brain injury. In a selected cohort at high prevalence of ICU delirium, we found that delirium was associated with significantly lower values of quantitative PLR and CV, which persisted over time, at the early ICU phase, irrespective of disease severity and analgesia-sedation dose. Our findings have both pathophysiological and clinical implications.

From the pathophysiological standpoint, reduced pupillary constriction in the delirious population, irrespective of age, opioid dose, and disease severity, supports the concept that cholinergic deficit may be a causal factor, thereby establishing a potential pathophysiological basis to our findings [31]. Automated infrared pupillometry may be a valid research tool to investigate autonomous nervous system dysfunction in

Table 3 Associations between pupillometry variables and delirium

\begin{tabular}{llll}
\hline Pupillometry variables & Delirium & No delirium & \\
\hline DAY 3 & & $2.9(2.3-3.4)$ & \\
Pupil size, mm & $2.4(2.2-2.9)$ & $25(19-31)$ & 0.137 \\
Quantitative PLR, \% pupil constriction & $20(15-28)$ & $2.5(1.7-2.8)$ & 0.012 \\
Constriction velocity, mm/s & $1.7(1.4-2.4)$ & & 0.017 \\
DAY 4 & & $3.0(2.5-4.0)$ \\
Pupil size, mm & $2.7(2.3-3.2)$ & $25(20-33)$ \\
Quantitative PLR, \% pupil constriction & $21(16-27)$ & $2.2(2.0-3.2)$ \\
Constriction velocity, mm/s & $1.7(1.5-2.6)$ & & 0.045 \\
DAY 5 & & $3.8(3.2-4.3)$ & 0.007 \\
Pupil size, mm & $3.1(2.5-3.8)$ & $31(25-37)$ & 0.014 \\
Quantitative PLR, \% pupil constriction & $25(17-32)$ & $3.5(2.6-3.6)$ & 0.011 \\
Constriction velocity, mm/s & $2.2(1.5-3.1)$ & 0.009 \\
\hline
\end{tabular}

Data are presented as median (25th-75th percentiles) Abbreviations: $C V$ constriction velocity, $P L R$ pupillary light reflex 
A. Quantitative PLR (\% pupillary constriction)

官 No delirium 官 Delirium

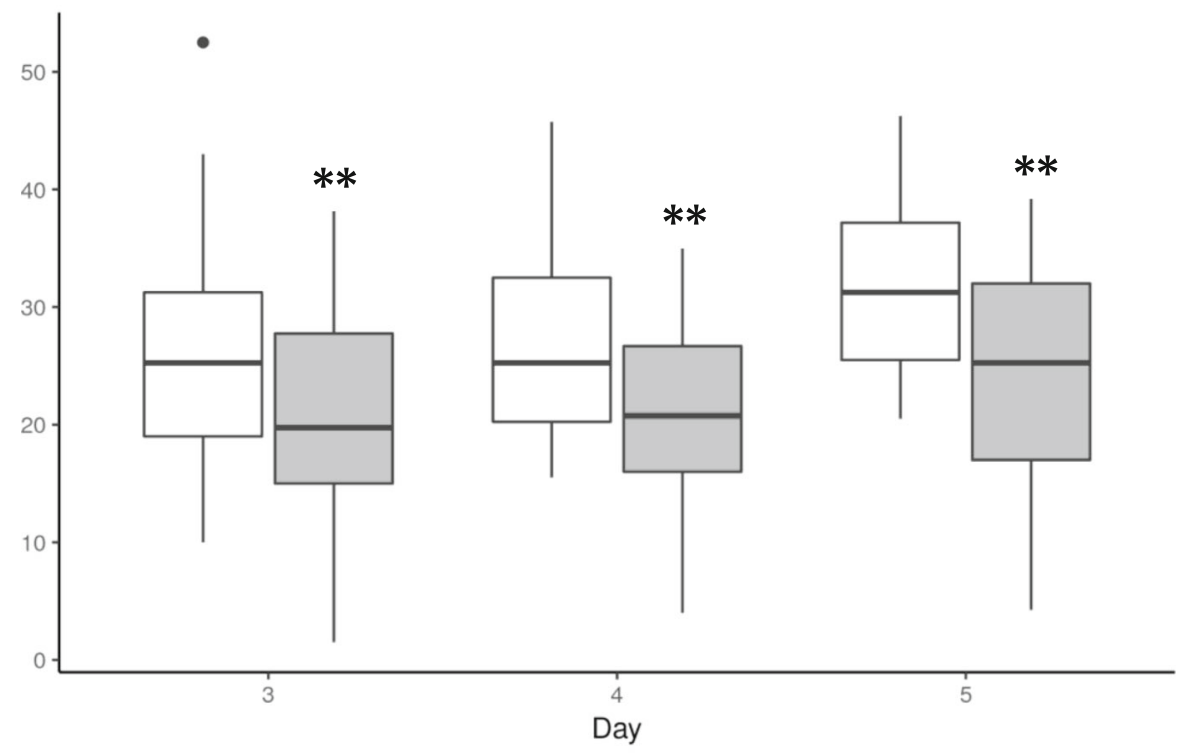

B. Constriction velocity $(\mathrm{mm} / \mathrm{sec})$

官 No delirium 官 Delirium

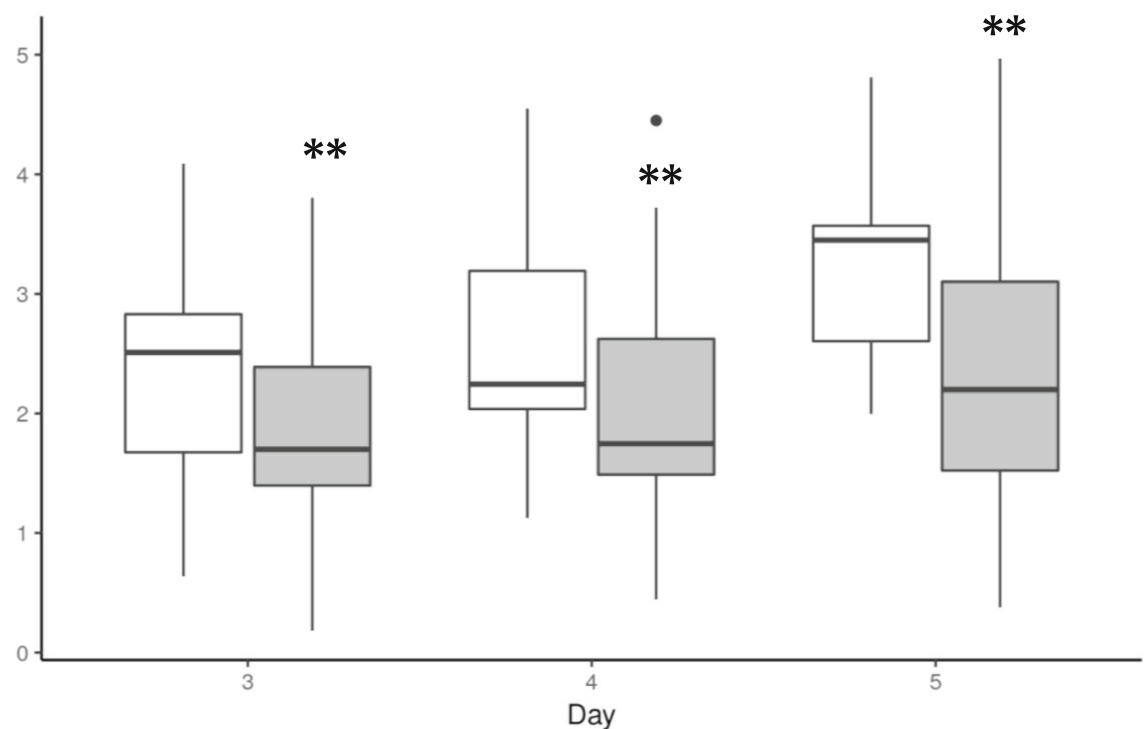

Fig. 1 Trends over time of quantitative pupillary light reflex (PLR) and constriction velocity in patients with and without delirium. ${ }^{* *} p<0.05$ for comparison between groups. a Quantitative PLR (\% pupillary constriction). b Constriction velocity $(\mathrm{mm} / \mathrm{s}$ ) 
Table 4 Multivariable logistic regression with independent risk factors for ICU delirium

\begin{tabular}{llll}
\hline Variable & $\begin{array}{l}\text { Odds } \\
\text { ratio }\end{array}$ & $\begin{array}{l}95 \% \text { confidence } \\
\text { interval }\end{array}$ & $P$ value \\
\hline Quantitative pupillary light reflex & 1.057 & $1.007-1.113$ & 0.03 \\
SOFA score & 1.140 & $0.981-1.337$ & 0.09 \\
Fentanyl dose & 1.005 & $0.999-1.013$ & 0.14 \\
Midazolam dose & 0.998 & $0.863-1.163$ & 0.98 \\
\hline
\end{tabular}

After adjustment for the SOFA score, and the cumulative dose of midazolam and fentanyl, lower quantitative pupillary light reflex at day 3 was associated with an increased risk of ICU delirium

critically ill patients $[32,33]$ and may be useful in future studies on ICU delirium.

From the clinical standpoint, our cohort is representative of an ICU population at high-risk for delirium (about 50\%), in which there are currently no monitoring tools for early delirium detection [24]. The delirium prevalence was comparable to other reports [26, 34, 35], and as previously observed, delirious subjects had higher cumulative analgesia-sedation dose [36, 37] and greater disease severity [38, 39]. Pupillary constriction is reduced by opioids [40] and sedatives [41]; however, the associations between ICU delirium and reduced q-PLR and CV remained statistically significant after adjusting for opioid and sedation dose, and no significant interaction was found between pupillary constriction variables and fentanyl or midazolam. We found that the best model for predicting delirium, with an area under the ROC curve of 0.71 , was the one combining q-PLR and SOFA score at day 3 . These findings imply that mechanically ventilated sedated patients with high SOFA score and low qPLR are at considerably higher risk of ICU delirium. In this patient population, automated infrared pupillometry may be of particular benefit. It is plausible to postulate that abnormally low quantitative pupillary constriction variables may trigger interventions targeted at limiting delirium risk, or complement available composite scores for predicting delirium [22].

\section{Study limitations}

The study was single-center and utilized a convenience sample size, without formal sample size calculation, thereby implying a potential risk of biases. The cohort was selected to be representative of a high-risk ICU delirium population, undergoing mechanically ventilation for at least $48 \mathrm{~h}$ or more, i.e., a setting where neuromonitoring may be of greatest potential utility. However, pupillometry was not started early on ICU admission in all patients expected to be on mechanical ventilation for at least $48 \mathrm{~h}$, but rather was restricted to patients who were actually still mechanically ventilated after $48 \mathrm{~h}$. It therefore remains to be investigated whether very early pupillometry assessment may provide even earlier evidence for risk of delirium. The duration of the delirium was not available in all patients, which is an additional limitation.

Neuroimaging was not systematically performed, but we excluded all patients admitted for a primary acute brain injury or with a previous known neurological disease thereby limiting as much as possible intrinsic brain factors that may potentially alter pupillometry assessment $[42,43]$. Furthermore, pupillometry measurements were performed by an experienced research ICU physician or nurse, thereby guaranteeing data reliability and quality, and the pupillometry data were blinded to clinicians involved in patient care. We did not adjust for ambient light conditions, which may at least in part affect q-PLR [44]. However, the pupillometer used in this study (AlgiScan ${ }^{\bullet}$ device) has a black rubber that completely covers the eye, thereby ensuring homogeneous dark conditions during pupillary constriction measurements. The average absolute difference in pupil constriction between delirious and non-delirious patients was relatively low-ranging from 0.2 to $0.3 \mathrm{~mm}$-which approaches the limits of inter-rater variability for the device [45]. Additional computed variables such as the Neurological Pupil index (NPi) [40] were not available in this study, but warrants further investigation. Our findings are hypotheses-generating: additional larger, ideally multicenter, studies are needed to confirm our data and more precisely assess the value of low q-PLR in predicting ICU delirium, and identify precise prognostic cutoffs in this setting.

\section{Conclusions}

Automated infrared pupillometry revealed a strong association between lower pupillary light constriction and ICU delirium, irrespective of baseline injury severity and cumulative analgesia and sedation dose. Importantly, alterations in quantitative pupillary constriction variables occurred early and preceded delirium diagnosis by a median 5 days. The findings of this study provide novel insights into ICU delirium pathophysiology and suggest a potential clinical utility of quantitative pupillometry for the neuromonitoring of sedated mechanically ventilated patients at high risk for ICU delirium.

\section{Acknowledgements \\ The authors would like to thank the nursing and medical teams for their help and support throughout the study.}

\section{Authors' contributions}

EF was involved in the data analysis and drafted the manuscript. AB performed the statistical analyses and critically revised the article. PM collected the data, contributed to the analyses, and revised the manuscript. JP performed statistics. JPM collected the data and critically revised the manuscript. SAM conducted protocol development and submission and regulatory aspects. NBH critically revised the manuscript. MO conceived the study, supervised the data analysis, and critically revised the manuscript. All the authors read and approved the final manuscript. 


\section{Funding}

Mauro Oddo is supported by research grants from the Swiss National Science Foundation.

\section{Availability of data and materials}

The datasets used and/or analyzed during the current study are available from the corresponding author on reasonable request.

\section{Ethics approval and consent to participate}

The study was approved by the ethical committee of the University of Lausanne (CER-VD), project-ID 2016-01923. A waiver of consent was provided, given pupillometry assessment is a standard of care.

\section{Consent for publication}

Not applicable.

\section{Competing interests}

The authors declare that they have no competing interests.

\section{Author details}

${ }^{1}$ Critical Care Research Unit, Centre Hospitalier Universitaire Vaudois (CHUV), University Hospital and University of Lausanne, Rue du Bugnon 46, BH08-623, CH-1011 Lausanne, Switzerland. ²Department of Intensive Care Medicine, Centre Hospitalier Universitaire Vaudois (CHUV), University Hospital and University of Lausanne, Rue du Bugnon 46, BH 08.623, Lausanne, Switzerland. ${ }^{3}$ Institute of Higher Education and Research in Healthcare - IUFRS, University of Lausanne, Lausanne, Switzerland. ${ }^{4}$ Center for Primary Care and Public Health, University of Lausanne, Lausanne, Switzerland.

Received: 22 December 2019 Accepted: 18 February 2020 Published online: 24 February 2020

\section{References}

1. Hayhurst CJ, Pandharipande PP, Hughes CG. Intensive care unit delirium: a review of diagnosis, prevention, and treatment. Anesthesiology. 2016;125(6): 1229-41.

2. Maldonado JR. Acute brain failure: pathophysiology, diagnosis, management, and sequelae of delirium. Crit Care Clin. 2017;33(3):461-519.

3. Lehner KR, Silverman HA, Addorisio ME, Roy A, Al-Onaizi MA, Levine $Y$, Olofsson PS, Chavan SS, Gros R, Nathanson NM et al: Forebrain cholinergic signaling regulates innate immune responses and inflammation. Front Immunol 2019, 10(585).

4. Pavlov VA, Chavan SS, Tracey KJ. Molecular and functional neuroscience in immunity. Annu Rev Immunol. 2018;36:783-812.

5. Chavan SS, Tracey KJ. Essential Neuroscience in Immunology. J Immunol. 2017;198(9):3389-97.

6. Rosas-Ballina M, Olofsson PS, Ochani M, Valdés-Ferrer SI, Levine YA, Reardon C, Tusche MW, Pavlov VA, Andersson U, Chavan S, et al. Acetylcholinesynthesizing $T$ cells relay neural signals in a vagus nerve circuit. Science. 2011;334(6052):98-101.

7. Andersson $U$, Tracey KJ. Reflex principles of immunological homeostasis. Annual Reviews. 2012:30(1):313-35.

8. Zaghloul N, Addorisio ME, Silverman HA, Patel HL, Valdés-Ferrer SI, Ayasolla KR, Lehner KR, Olofsson PS, Nasim M, Metz CN et al: Forebrain cholinergic dysfunction and systemic and brain inflammation in murine sepsis survivors. Front Immunol 2017, 8(1673)

9. Huffman WJ, Subramaniyan S, Rodriguiz RM, Wetsel WC, Grill WM, Terrando N. Modulation of neuroinflammation and memory dysfunction using percutaneous vagus nerve stimulation in mice. Brain Stimulation. 2019;12(1): 19-29.

10. Frasch MG, Szynkaruk M, Prout AP, Nygard K, Cao M, Veldhuizen R, Hammond R, Richardson BS. Decreased neuroinflammation correlates to higher vagus nerve activity fluctuations in near-term ovine fetuses: a case for the afferent cholinergic anti-inflammatory pathway? J Neuroinflammation. 2016;13(1):103.

11. Cai PY, Bodhit A, Derequito R, Ansari S, Abukhalil F, Thenkabail S, Ganji S, Saravanapavan P, Shekar CC, Bidari S et al: Vagus nerve stimulation in ischemic stroke: old wine in a new bottle. Front Neurol 2014, 5(107).

12. Schweighöfer $\mathrm{H}$, Rummel $\mathrm{C}$, Roth J, Rosengarten B. Modulatory effects of vagal stimulation on neurophysiological parameters and the cellular immune response in the rat brain during systemic inflammation. Intensive Care Med Exp. 2016;4(1):19.

13. Fernandez R, Nardocci G, Navarro C, Reyes EP, Acuña-Castillo C, Cortes PP: Neural reflex regulation of systemic inflammation: potential new targets for sepsis therapy. Front Neurol 2014, 5(489).

14. Wang Y, Zekveld AA, Naylor G, Ohlenforst B, Jansma EP, Lorens A, Lunner T, Kramer SE. Parasympathetic nervous system dysfunction, as identified by pupil light reflex, and its possible connection to hearing impairment. PLoS One. 2016;11(4):e0153566.

15. Milioni ALV, Nagy BV, Moura ALA, Zachi EC, Barboni MTS, Ventura DF. Neurotoxic impact of mercury on the central nervous system evaluated by neuropsychological tests and on the autonomic nervous system evaluated by dynamic pupillometry. NeuroToxicology. 2017;59:263-9.

16. Moog P, Eren O, Kossegg S, Valda K, Straube A, Grünke M, Schulze-Koops H, Witt MJCAR. Pupillary autonomic dysfunction in patients with ANCAassociated vasculitis. Clin Auton Res. 2017;27(6):385-92.

17. Muppidi S, Adams-Huet B, Tajzoy E, Scribner M, Blazek P, Spaeth EB, Frohman E, Davis S, Vernino SJCAR. Dynamic pupillometry as an autonomic testing tool. Clin Auton Res. 2013;23(6):297-303.

18. Kaltsatou A, Fotiou D, Tsiptsios D, Orologas A. Cognitive impairment as a central cholinergic deficit in patients with myasthenia gravis. BBA Clinical. 2015;3:299-303.

19. Chougule PS, Najjar RP, Finkelstein MT, Kandiah N, Milea D: Light-induced pupillary responses in Alzheimer's disease. Front Neurol 2019, 10(360).

20. Mukherjee S, Vernino S. Dysfunction of the pupillary light reflex in experimental autoimmune autonomic ganglionopathy. Auton Neurosci. 2007:137(1):19-26.

21. Fotiou DF, Stergiou V, Tsiptsios D, Lithari C, Nakou M, Karlovasitou A. Cholinergic deficiency in Alzheimer's and Parkinson's disease: evaluation with pupillometry. Int J Psychophysiol. 2009;73(2):143-9.

22. Wassenaar A, van den Boogaard M, van Achterberg T, Slooter AJC, Kuiper MA, Hoogendoorn ME, Simons KS, Maseda E, Pinto N, Jones C, et al. Multinational development and validation of an early prediction model for delirium in ICU patients. Intensive Care Med. 2015:41(6):1048-56.

23. van den Boogaard M, Schoonhoven L, Evers AW, van der Hoeven JG, van Achterberg T, Pickkers P. Delirium in critically ill patients: impact on longterm health-related quality of life and cognitive functioning. Crit Care Med. 2012;40(1):112-8.

24. Pandharipande PP, Ely EW, Arora RC, Balas MC, Boustani MA, La Calle GH, Cunningham C, Devlin JW, Elefante J, Han JH, et al. The intensive care delirium research agenda: a multinational, interprofessional perspective. Intensive Care Med. 2017:43(9):1329-39.

25. Devlin JW, Skrobik Y, Gelinas C, Needham DM, Slooter AJC, Pandharipande PP, Watson PL, Weinhouse GL, Nunnally ME, Rochwerg B, et al. Clinical practice guidelines for the prevention and management of pain, agitation/ sedation, delirium, immobility, and sleep disruption in adult patients in the ICU. Crit Care Med. 2018;46(9):e825-73.

26. Mehta S, Cook D, Devlin JW, Skrobik Y, Meade M, Fergusson D, Herridge M, Steinberg M, Granton J, Ferguson N, et al. Prevalence, risk factors, and outcomes of delirium in mechanically ventilated adults. Crit Care Med. 2015; 43(3):557-66.

27. Sauder P, Andreoletti M, Cambonie G, Capellier G, Feissel M, Gall O, Goldran-Toledano D, Kierzek G, Mateo J, Mentec H, et al. Sedation and analgesia in intensive care (with the exception of new-born babies). French Society of Anesthesia and Resuscitation. French-speaking resuscitation society. Annales francaises d'anesthesie et de reanimation. 2008;27(7-8): 541-51.

28. Ely EW, Truman B, Shintani A, Thomason JW, Wheeler AP, Gordon S, Francis J, Speroff T, Gautam S, Margolin R, et al. Monitoring sedation status over time in ICU patients: reliability and validity of the Richmond AgitationSedation Scale (RASS). Jama. 2003;289(22):2983-91.

29. Taylor WR, Chen JW, Meltzer H, Gennarelli TA, Kelbch C, Knowlton S, Richardson J, Lutch MJ, Farin A, Hults KN, et al. Quantitative pupillometry, a new technology: normative data and preliminary observations in patients with acute head injury. J Neurosurg. 2003;98(1):205.

30. Singer M, Deutschman CS, Seymour CW, Shankar-Hari M, Annane D, Bauer M, Bellomo R, Bernard GR, Chiche J-D, Coopersmith CM, et al. The Third International Consensus Definitions for Sepsis and Septic Shock (Sepsis-3). Jama. 2016;315(8):801-10.

31. Rohaut B, Porcher R, Hissem T, Heming N, Chillet P, Djedaini K, Moneger G, Kandelman S, Allary J, Cariou A, et al. Brainstem response patterns in 
deeply-sedated critically-ill patients predict 28-day mortality. PLoS One. 2017;12(4):e0176012.

32. Phillips SS, Mueller CM, Nogueira RG, Khalifa YMJNC. A systematic review assessing the current state of automated pupillometry in the NeurolCU. Neurocrit Care. 2019;31(1):142-61.

33. Hall CA, Chilcott RP. Eyeing up the Future of the Pupillary Light Reflex in Neurodiagnostics. Diagnostics (Basel, Switzerland). 2018;8(1):19.

34. Ely EW, Shintani A, Truman B, Speroff T, Gordon SM, Harrell J, Frank E, Inouye SK, Bernard GR, Dittus RS. Delirium as a predictor of mortality in mechanically ventilated patients in the intensive care unit. Jama. 2004; 291(14):1753-62

35. Pandharipande P, Cotton BA, Shintani A, Thompson J, Pun BT, Morris JA Jr, Dittus R, Ely EW. Prevalence and risk factors for development of delirium in surgical and trauma intensive care unit patients. J Trauma. 2008;65(1):34-41.

36. Reade $M C$, Finfer $S$. Sedation and delirium in the intensive care unit. $N$ Engl J Med. 2014;370(5):444-54.

37. Mattar I, Chan MF, Childs C. Factors causing acute delirium in critically ill adult patients: a systematic review. JBI Library of Systematic Review. 2012; 10(3):187-231.

38. Zaal IJ, Devlin JW, Peelen LM, Slooter AJ. A systematic review of risk factors for delirium in the ICU. Crit Care Med. 2015;43(1):40-7.

39. Patel SB, Poston JT, Pohlman A, Hall JB, Kress JP: Rapidly reversible, sedation-related delirium versus persistent delirium in the intensive care unit. Am J Respir Crit Care Med. 2014:189(6):658-665.

40. Morelli P, Oddo M, Ben-Hamouda N. Role of automated pupillometry in critically ill patients. Minerva Anestesiology. 2019;85:995-1002

41. Larson MD, Behrends M. Portable infrared pupillometry: a review. Anesth Analg. 2015;120(6):1242-53.

42. Solari D, Rossetti AO, Carteron L, Miroz JP, Novy J, Eckert P, Oddo M. Early prediction of coma recovery after cardiac arrest with blinded pupillometry. Ann Neurol. 2017;81(6):804-10.

43. Jahns F-P, Miroz JP, Messerer M, Daniel RT, Taccone FS, Eckert P, Oddo MJCC: Quantitative pupillometry for the monitoring of intracranial hypertension in patients with severe traumatic brain injury 2019, 23(1):155.

44. Ong C, Hutch M, Smirnakis SJNC. The effect of ambient light conditions on quantitative pupillometry. Neurocrit Care. 2019;30(2):316-21.

45. Couret D, Boumaza D, Grisotto C, Triglia T, Pellegrini L, Ocquidant P, Bruder $N J$, Velly $L$. Reliability of standard pupillometry practice in neurocritical care: an observational, double-blinded study. Crit Care. 2016;20(1):99.

\section{Publisher's Note}

Springer Nature remains neutral with regard to jurisdictional claims in published maps and institutional affiliations.

Ready to submit your research? Choose BMC and benefit from:

- fast, convenient online submission

- thorough peer review by experienced researchers in your field

- rapid publication on acceptance

- support for research data, including large and complex data types

- gold Open Access which fosters wider collaboration and increased citations

- maximum visibility for your research: over $100 \mathrm{M}$ website views per year

At $\mathrm{BMC}$, research is always in progress.

Learn more biomedcentral.com/submissions 